\title{
Analysis of CEOs with Overseas Backgrounds on Easing Corporate Financing Constraints
}

\author{
Can Yao \\ Yunnan University of Finance and Economics, Yunnan, China \\ yaocan1869@163.com
}

\begin{abstract}
This paper uses China's A-share listed companies in Shanghai and Shenzhen stock exchanges from 2008 to 2018 as a sample to explore the relationship between the CEO's overseas background and corporate financing constraints. The empirical results show that the CEO's overseas background has a significant impact on corporate financing constraints. Further research results show that the CEO of a state-owned enterprise can significantly alleviate the level of corporate financing constraints under the conditions of an overseas background, while the CEO's nonconcurrent directorship can strengthen the impact of the CEO's overseas background on corporate financing constraints.
\end{abstract}

Keywords: Financing Constraints; CEO's Overseas Background; Nature of Property Rights; Two Jobs in One.

\section{Introduction}

Based on the current situation of difficult and expensive financing of Chinese enterprises, the government's task in 2019 is to reduce the financing costs of enterprises. Since Fazzari et al. (1988) formally proposed the concept of "financing constraints", the issue of financing constraints has received extensive attention from academia. Financing constraints not only seriously affect the growth and performance of enterprises (Campello et al., 2010), the economic development of the entire country will also be negatively affected. Therefore, in the context of China's current transitional economy, studying the influencing factors of corporate financing constraints has strong practical guiding significance.

MM theory is studied purely from the perspective of the capital market. However, in reality, because of the existence of information asymmetry (Fazzari, 1988), the issue of financing constraints has always been the enterprise's A big difficulty. The existing literature has many studies on the influencing factors of financing constraints, and found that agency costs (Kaplan and Zingales, 1997), the degree of regional financial development (Wei Zhihua et al., 2014), monetary policy (Jin Qinglu et al., 2012) will affect corporate financing. Most of these studies assume that managers are homogeneous, but ignore In view of the potential impact of managerial heterogeneity, the important mechanism of CEO background characteristics is rarely mentioned.

Although there are a few literatures that examine manager-level characteristics, most of these studies are based on the perspective of corporate governance. In view of this, this paper focuses on the impact of the CEO's overseas background on corporate financing constraints and its internal mechanism. Taking the data of A-share listed companies in Shanghai and Shenzhen stock exchanges from 2008 to 2018 as a sample, this paper examines the relationship between the CEO's overseas background and corporate financing constraints. The results show that the CEO's overseas background is significantly negatively correlated with the level of corporate financing constraints.

The contribution of this paper is mainly reflected in the following two aspects: First, this article has enriched the relevant research in the field of managerial characteristics. Second, this article enriches the relevant research on the factors affecting corporate financing constraints. And the remaining parts are arranged as follows: The second part reviews the relevant literature and proposes the research hypothesis of this article on the basis of the existing literature and theories; the third part is the research design of this article; the fourth part reports the main empirical results of this article ; The fifth part further studies the relationship between the CEO's overseas background and corporate 
Volume 15 (2021)

financing constraints; the sixth part is a robustness test; the seventh part is a brief summary of this article.

\section{Theoretical Analysis and Research Hypothesis}

Traditional financing constraint theory believes that information asymmetry, agency problems and transaction costs are the main reasons for financing constraints. Since the extent to which a company faces financing restrictions depends not only on the macro environment, but also on the internal operating conditions of the company. The high-level team theory believes that the CEO is one of the core figures of the executive team. Every strategic choice will have an important impact on the longterm development of the company. Han Liyan and Li Hui (2009) pointed out that this core position determines that the greater the CEO's power, the stronger his control over the company, the greater the impact on the decision-making process, and the greater the impact on the entire company. Therefore, the different impacts of the differences in managerial characteristics on research should not be ignored.

This paper believes that the CEO's overseas background can ease corporate financing constraints. First, the CEO's overseas background can affect financial flexibility, which in turn affects corporate financing constraints. Secondly, the CEO's overseas background may affect the company's capital structure and accounting policies, which in turn affects the company's financing constraints. Finally, the CEO's overseas background can affect the company's earnings management, which in turn affects financing constraints. According to the branding theory, as the main makers of business decisionmaking, they can use the branding influence of cognition and ability affects financing constraints.

Based on the above analysis, this article believes that when the CEO has the characteristics of an overseas background, corporate financing constraints will be significantly eased. Accordingly, this article proposes hypothesis 1:

H1a: Under other conditions unchanged, the CEO's overseas background is negatively correlated with the level of corporate financing constraints.

H1b: Under other conditions unchanged, the CEO's overseas background is positively correlated with the level of corporate financing constraints.

\section{Research and Design}

\subsection{Sample Selection and Data Sources}

This article selects all A-share listed companies on the Shanghai and Shenzhen stock exchanges from 2008 to 2018 as the initial sample, and selects the original sample according to the following conditions: (1) Taking into account the particularities of the financial and insurance industries, this article excludes finance and insurance Industry samples. (2) Exclude samples in abnormal trading conditions such as ST and *ST. (3) Eliminate the missing financial data required in the research and the observations with unknown CEO background information disclosure. After the above screening, 23367 observations were finally obtained in this paper. The data used in this article comes from the annual financial reports of listed companies provided by the CSMAR Cathay Pacific database and Wind database. In addition, in order to avoid extreme values from affecting the regression results, this paper has carried out tailing treatment on all continuous variables at the $1 \%$ and $99 \%$ quantiles.

\subsection{Model Construction and Variable Definition}

1. Explained variable: corporate financing constraints (FC). With reference to the practice of Hadlock and Pierce (2010), the SA index is constructed using two relatively exogenous variables of firm size and age to measure the degree of corporate financing constraints. Therefore, this article uses the SA index to measure the financing constraints of a company. The larger the SA index, the more severe the financing constraints of the company. 
2. Explanatory variable: CEO overseas background (Overseas). Drawing on the practice of Duan and Hou (2014), overseas background mainly refers to overseas study or work experience. This article uses the method of setting dummy variables to measure the CEO's overseas background (Overseas). If the CEO has overseas study or employment experience, then This variable is 1 , otherwise it is 0 .

3. Regulating variables: (1) The nature of property rights (Soe). The value of state-owned enterprises is 1 , and the value of non-state-owned enterprises is 0 . (2) Dual. The value is 1 when the chairman and general manager are concurrently serving, otherwise the value is 0 .

4.Research model: This paper draws on the practice of Wu Qiusheng and Huang Xianhuan (2017) to calculate the SA index:|-0.737Size+0.043Size2-0.04 Age |, Among them, Size=ln (total assets/ 1000000), Age is the company's listing years. The index is an absolute value. The larger the value, the more serious the financial constraints of the company. This paper constructs an empirical model of corporate financing constraints as follows:

$$
\begin{aligned}
& \text { SA } A_{i, t}=a_{0}+a_{1} \text { Overseas }_{t, t}+a_{2} \text { Lev }_{i, t}+a_{3} \text { Growth }_{t, t}+a_{4} \text { Roa }_{i, t}+a_{5} \text { Board }_{i, t}+a_{6} \text { Indep }_{i, t} \\
& +a_{7} \text { IC }_{i, t}+a_{8} \text { Dual }_{i, t}+a_{9} \text { First }_{i, t}+a_{10} \text { Soe }_{i, t}+\sum \text { Year }+\sum \text { Ind }+\varepsilon_{i, t}
\end{aligned}
$$

$\varepsilon$ is the residual item. At the same time, using the practice of Zhong Qiuyan and Shi Xiaofeng (2016), the control variables are selected: size of the enterprise(Size); Lev of asset-liability ratio(Lev); age of the enterprise(Age); growth(Growth); enterprise performance(Roa); Board size Board(Board); proportion of independent directors(Indep); internal control quality(IC); two-time integration(Dual); equity concentration(First); property rights(Soe). Year is the annual dummy variable, and Ind is the industry dummy variable.

\section{Empirical Results and Analysis}

\subsection{Descriptive Statistical Analysis}

Table 1 reports the descriptive statistical results of the main variables in this paper. The mean value of FC in the sample is 3.7553 , the median is 3.7578 , the minimum is 3.0916 , and the maximum is 4.3467. The sample distribution is relatively uniform. The differences in the degree of financing constraints of each company in the sample are relatively small. The standard deviation is 0.2447 , indicating that the fluctuation of corporate financing constraints around the mean is not very large. The minimum, upper quartile, and median of Overseas are all 0 , indicating that it is common for CEOs to have no overseas background in listed companies in my country.

Table 1. Descriptive statistics of main variables

\begin{tabular}{|c|c|c|c|c|c|c|c|}
\hline Variable & $\mathrm{N}$ & mean & $\mathrm{sd}$ & $\mathrm{p} 50$ & $\mathrm{p} 75$ & $\min$ & $\max$ \\
\hline FC & 23367 & 3.7553 & 0.2447 & 3.7578 & 3.9172 & 3.0916 & 4.3467 \\
\hline Overseas & 23367 & 0.0684 & 0.2525 & 0.0000 & 0.0000 & 0.0000 & 1.0000 \\
\hline Size & 23367 & 21.8567 & 1.2092 & 21.7151 & 22.5432 & 19.2641 & 25.5044 \\
\hline Lev & 23367 & 0.3814 & 0.2219 & 0.3665 & 0.5413 & 0.0048 & 0.9593 \\
\hline Age & 23367 & 16.9082 & 5.5071 & 17.0000 & 21.0000 & 5.0000 & 31.0000 \\
\hline Growth & 23367 & 0.2097 & 0.5217 & 0.1203 & 0.2889 & -0.5912 & 3.7051 \\
\hline Roa & 23367 & 0.0489 & 0.0724 & 0.0453 & 0.0810 & -0.2642 & 0.2807 \\
\hline Board & 23057 & 2.2625 & 0.1770 & 2.3026 & 2.3026 & 1.7918 & 2.7726 \\
\hline Indep & 23057 & 0.3714 & 0.0523 & 0.3333 & 0.4286 & 0.3077 & 0.5714 \\
\hline IC & 22991 & 644.4490 & 142.3444 & 673.1300 & 707.2400 & 0.0000 & 902.3500 \\
\hline Dual & 23367 & 0.2455 & 0.4304 & 0.0000 & 0.0000 & 0.0000 & 1.0000 \\
\hline First & 23367 & 35.2982 & 15.0351 & 33.3682 & 45.6172 & 8.6308 & 75.0045 \\
\hline
\end{tabular}




\subsection{Correlation Analysis}

Table 2 reports the correlation coefficients between the respective variables. The correlation coefficient between Overseas and FC is -0.027 , which is a significant negative correlation at the $1 \%$ level, which initially validates the hypothesis 1 . It shows that CEO's overseas background can alleviate corporate financing constraints. At the same time, the correlation coefficients between most explanatory variables are less than 0.5 , indicating that there is no obvious multicollinearity problem among explanatory variables.

Table 2. Correlation coefficient of main variables

\begin{tabular}{|c|c|c|c|c|c|c|c|c|c|c|c|c|}
\hline & $\mathrm{FC}$ & Overseas & Lev & Size & Age & Growth & Roa & Board & Indep & IC & Dual & First \\
\hline FC & 1 & & & & & & & & & & & \\
\hline Overseas & $-0.027 * * *$ & 1 & & & & & & & & & & \\
\hline Lev & 0.004 & $-0.064 * * *$ & 1 & & & & & & & & & \\
\hline Size & $0.070 * * *$ & -0.010 & $0.309 * * *$ & 1 & & & & & & & & \\
\hline Age & $0.892 * * *$ & $-0.027 * * *$ & $0.050 * * *$ & $0.113 * * *$ & 1 & & & & & & & \\
\hline Growth & 0.003 & $0.015 * *$ & $-0.027 * * *$ & $0.034 * * *$ & -0.008 & 1 & & & & & & \\
\hline Roa & -0.001 & $0.017 * * *$ & $-0.305 * * *$ & $0.057 * * *$ & $-0.012 *$ & $0.180 * * *$ & 1 & & & & & \\
\hline Board & -0.001 & $-0.054 * * *$ & $0.136^{* * *}$ & $0.270 * * *$ & 0.002 & $-0.024 * * *$ & $0.017 * * *$ & 1 & & & & \\
\hline Indep & $-0.057 * * *$ & $0.041 * * *$ & $-0.018 * * *$ & $0.023 * * *$ & $-0.015 * *$ & 0.007 & $-0.021 * * *$ & $-0.486 * * *$ & 1 & & & \\
\hline IC & $-0.092 * * *$ & 0.004 & $-0.094 * * *$ & $0.210 * * *$ & $-0.124 * * *$ & $0.073 * * *$ & $0.361 * * *$ & $0.078 * * *$ & 0.001 & 1 & & \\
\hline Dual & $-0.078 * * *$ & $0.063 * * *$ & $-0.114 * * *$ & $-0.154 * * *$ & $-0.077 * * *$ & $0.018^{* * *}$ & $0.018^{* * *}$ & $-0.178 * * *$ & $0.106 * * *$ & $-0.024 * * *$ & 1 & \\
\hline First & $-0.145 * * *$ & $-0.023 * * *$ & $0.024 * * *$ & $0.231 * * *$ & $-0.131 * * *$ & $0.018^{* * *}$ & $0.122 * * *$ & $0.027 * * *$ & $0.041 * * *$ & $0.131 * * *$ & $-0.056 * * *$ & 1 \\
\hline
\end{tabular}

Note: $* * *, * *, *$ indicate the significance level of $1 \%, 5 \%$, and $10 \%$ respectively, the same below.

\subsection{Analysis of Multiple Regression Results}

Table 3. The impact of CEO's overseas background on financing constraints

\begin{tabular}{|c|c|c|c|c|}
\hline & (1) & (2) & (3) & (4) \\
\hline \multirow[t]{2}{*}{ Overseas } & $-0.0261 * * *$ & $-0.0368 * * *$ & $-0.0067 * *$ & $-0.0056^{*}$ \\
\hline & $(-3.8571)$ & $(-5.9451)$ & $(-2.2710)$ & $(-1.8868)$ \\
\hline \multirow[t]{2}{*}{ Lev } & & & $-0.0216^{* * *}$ & $-0.0184 * * *$ \\
\hline & & & $(-4.1102)$ & $(-3.3234)$ \\
\hline \multirow[t]{2}{*}{ Size } & & & $-0.0038 * * *$ & $-0.0050 * * *$ \\
\hline & & & $(-2.7693)$ & $(-3.6622)$ \\
\hline \multirow[t]{2}{*}{ Age } & & & $0.0393 * * *$ & $0.0390 * * *$ \\
\hline & & & $(263.4984)$ & $(259.8031)$ \\
\hline \multirow[t]{2}{*}{ Growth } & & & $0.0059 * * *$ & $0.0055^{* * *}$ \\
\hline & & & $(3.3662)$ & $(3.0469)$ \\
\hline \multirow[t]{2}{*}{ Roa } & & & & -0.0289 \\
\hline & & & & $(-1.6298)$ \\
\hline \multirow[t]{2}{*}{ Board } & & & & $-0.0187 * * *$ \\
\hline & & & & $(-3.3459)$ \\
\hline \multirow[t]{2}{*}{ Indep } & & & & $-0.2282 * * *$ \\
\hline & & & & $(-12.5708)$ \\
\hline \multirow[t]{2}{*}{ IC } & & & & $0.0001 * * *$ \\
\hline & & & & $(5.9771)$ \\
\hline \multirow[t]{2}{*}{ Dual } & & & & $-0.0106^{* * *}$ \\
\hline & & & & $(-6.0044)$ \\
\hline \multirow[t]{2}{*}{ First } & & & & $-0.0003 * * *$ \\
\hline & & & & $(-5.3968)$ \\
\hline \multirow[t]{2}{*}{ Constant } & $3.7570 * * *$ & $3.5566 * * *$ & $3.1756 * * *$ & $3.3068 * * *$ \\
\hline & $(2.3 \mathrm{e}+03)$ & $(311.5617)$ & $(110.4343)$ & $(105.0038)$ \\
\hline $\mathrm{N}$ & 23,367 & 23,367 & 23,367 & 22,689 \\
\hline Adj.R2 & 0.0007 & 0.2138 & 0.8042 & 0.8060 \\
\hline
\end{tabular}

Note: The standard deviation of the estimated value is in parentheses, the same below. 
Table 3 reports the multiple regression results of the impact of the CEO's overseas background on corporate financing constraints. Column (1): without adding control variables, the regression coefficient of FC is -0.0261 , which is significantly negative at the $1 \%$ level; Column (2): with controlling the year and industry effects, the regression coefficient is -0.0368 , and it is significantly negative at the $1 \%$ level; column (3) adds the basic characteristics of the company to further control the year and industry effects, the coefficient is -0.0067 , and is significantly negative at the $5 \%$ level; column (4): after adding the corporate governance control variable to the regression of column (3), the regression coefficient is -0.0056 , and it is at $10 \%$ level is significantly negative, which validates the hypothesis H1a in this article. This shows that the CEO's overseas background can alleviate financing constraints to a certain extent, and supports the research hypothesis of this article.

\section{Further Research}

\subsection{Nature of Property Rights}

State-owned enterprises and non-state-owned enterprises face different degrees of financing constraints. State-owned enterprises have more financing channels and lower financing costs, while non-state-owned enterprises face More serious financing constraints (Luo Danglun and Zhen Liming, 2008). This paper will further divide enterprise ownership and conduct sub-sample analysis. The results show that state-owned enterprises are significantly negative, and non-state-owned enterprises are not significant. Mitigation, the hypothesis is verified. In summary, compared with non-stateowned listed companies, the CEO's overseas background is slightly more significant in the process of its effect on state-owned listed companies.

\subsection{Combination of Two Jobs}

The integration of two positions is a specific leadership structure in which the CEO of the company concurrently serves as the chairman of the board of directors. Brickley et al. (1997) believe that the integration of the two positions is one of the ways to reduce information exchange barriers, decisionmaking conflicts between the chairman and executives, and to improve the efficiency of company operations. This paper divides the sample according to two-time integration and two-time nonintegration. The results show that the regression coefficient of FC is not significant when the CEO is concurrently a director. But it are significantly negative at the $5 \%$ level when the two positions are not concurrently serving. This result confirms the hypothesis that the overseas background of the twotime CEO has little effect on the financing constraints of the company, and the two-time CEO can alleviate the level of financing constraints of the company to a certain extent.

\section{Robustness Test}

This paper conducts the following robustness tests: (1) Calculate the KZ index of each company every year to measure financing constraints. The larger the KZ value, the more severe the company's financing constraints. (2) Use individual fixed effects models to control the impact of specific factors at the enterprise level. After the above various robustness tests, the conclusions of this article are still valid, indicating that the results are robust.

\section{Conclusion and Enlightenment}

This paper uses the above analysis methods to construct financing constraint indicators. And it empirically tests the impact of the CEO's overseas background on corporate financing constraints. The results show that companies that CEO has overseas backgrounds have lower financing constraints, and this result is still valid even after controlling for potential endogeneity. Further research found that in state-owned enterprises, the CEO's overseas background has a significant increase in the 
impact of corporate financing constraints; at the same time, the CEO's overseas background has a significant reduction in the impact of corporate financing constraints in two-job companies.

The research in this article not only enriches the economic consequences of the CEO's overseas background and the relevant literature in the field of financing constraints, but enriches the research on the characteristics of managers and corporate governance. At the same time, the research conclusions of this paper have certain enlightening significance for the introduction of talents, improving the external environment of enterprises, and helping enterprises to alleviate financing constraints. However, this article still has certain shortcomings: a large sample of data can be obtained from public databases to measure the CEO's overseas background. However, this measurement method has certain aspects. noise. Therefore, how to measure the CEO's overseas background more objectively is worthy of further exploration in the future.

\section{Acknowledgments}

I would like to express my gratitude to all those who helped me during the writing of this thesis.

\section{References}

[1] Du Yong, Zhang Huan, Chen Jianying. CEO overseas experience and corporate earnings management[J]. Accounting Research, 2018(02): 27-33.

[2] Du Yong, Xie Jin, Chen Jianying. CEO financial background and real enterprise financialization[J]. China Industrial Economics, 2019(05):136-154.

[3] Deng Bofu, Tao Cunjie, Geely. Enterprises participate in targeted poverty alleviation and alleviate financing constraints [J]. Finance and Economics Research, 2020, 46(12): 138-151. 